\title{
Perancangan Kontroler Neural Network Pi untuk Sistem Pengaturan Level dengan Metode Decoupling Pada Plant Coupled Tank
}

\author{
Kresna KSP, Rusdhianto Effendie \\ Jurusan Teknik Elektro, Fakultas Teknologi Industri, Institut Teknologi Sepuluh Nopember (ITS) \\ Kampus ITS Sukolilo, Surabaya 60111 \\ E-mail:kresnakartika@ rocketmail.com-Rusdhi@elect-eng.its.ac.id
}

\begin{abstract}
Abstrak - Pada industri proses yang melibatkan fluida, suatu fluida akan dipompa dan dialirkan dari satu tangki ke tangki yang lain untuk diolah. Pemindahan cairan dari satu tangki ke tangki yang lain meyebabkan berubahnya level fluida dalam tangki. Dalam pengaturan level, pemindahan cairan biasa disebut sebagai pembebanan pada level.proses decoupling digunakan untuk mengubah dimana proses MIMO menjadi SISO agar lebih mudah dikontrol. Perubahan beban ini dapat mempengaruhi dari kinerja kontroler.. Kontroler yang banyak digunakan di industri proses adalah kontroler PI karena kesederhanaan struktur dan kehandalannya. Pada penerapan kontroler PID tuning parameter kontroler sering dilakukan dengan prosedur trial and error. Untuk tetap memenuhi spesifikasi kontrol yang diharapkan maka perlu dilakukan tuning ulang parameter kontroler PI. Kontroler PI Neural Network ini didesain untuk dapat melakukan tuning pada parameter kontroler PI sehingga dapat mengatasi perubahan parameter pada plant dan menjaga performa dari plant.setelah itu didapatkan performa dari plant yaitu berupa error steady state $\mathbf{0 . 0 3 2 \%}$ kemudian nilai Kp dan nilai Ki yaitu 15,043 dan 0.8071 .
\end{abstract}

Kata Kunci-Neural Network, Coupled tanks, Dekopling, Kontroler PI

\section{PENDAHULUAN}

Sistem pengendalian di industri merupakan faktor yang sangat penting dalam proses produksi. Agar produksi tetap tercapai, maka suatu sistem pengendalian sangat diperlukan untuk menjaga kestabilan variabel proses. Variabel proses antara lain temperature, pressure, flow, level, konsentrasi, volume dan lain sebagainya.

Coupled Tank tersusun dari dua buah tangki yang dihubungkan oleh sebuah pipa atau lubang saluran. Level cairan pada tangki pertama ditunjukkan sebagai $\mathrm{H}_{1}$ dan $\mathrm{H}_{2}$ adalah level tangki kedua. Bila input kontrol adalah flow $\mathrm{Q}_{1}$, maka variabel yang akan dikontrol adalah kedua Level $\mathrm{H}_{1}$ dan $\mathrm{H}_{2}$, dengan disturbance yang disebabkan oleh variasi flow pada valve $\mathrm{A}$, valve $\mathrm{B}$. Disini akan timbul suatu sistem dengan dua tangki saling berinteraksi.

Sistem Coupled Tank dapat dikonfigurasi sebagai sestem SISO atau sebagai Sistem MIMO melalui manpulasi input dan sectional daerah valve.

Sistem pengaturan merupakan otak dari plant level Coupled Tank. Dengan sistem pengaturan, plant level dapat digunakan untuk melakukan sesuatu yang berguna. Pengaturan didapat dari komponen yang mengubah kecepatan aliran air dan volume aliran guna mengatur level air yang diinginkan. Komponen pengaturan biasanya diletakkan pada tempat yang berbeda-beda.

Pemodelan coupled tanks termasuk kategori sistem nonlinear yang memiliki banyak ketidakpastian. Ketidakpastian tersebut dapat berupa gangguan eksternal, ketidakpastian model, variasi parameter, ataupun error yang muncul pada saat linierisasi. Ketidakpastian-ketidakpastian ini dapat mempengaruhi kestabilan sistem jika tidak diantisipasi oleh sistem kontrol. Selain itu, pemodelan coupled tanks menggunakan konfigurasi sistem Multi Input Multi Output (MIMO) [1]. Sehingga variabel yang diatur pada coupled tanks mengalami kesulitan mengikuti sinyal referensi berupa beberapa kondisi titik operasi yang diinginkan [2].

Untuk mengatasi permasalahan tersebut dibuatkan model sistem kontrol menggunakan dekopling untuk mengatur konfigurasi plant MIMO dan kontrol PI untuk mengatur level. Namun penentuan parameter dengan menggunakan metode try and error tidak efektif karena harus mencoba berulang kali untuk mendapatkan hasil optimal. Maka pada penelitian ini digunakan metode PI dan menggunakan neural network untuk tuning parameter dari kontroler. Kemudian plant dan sistem kontrol disimulasikan menggunakan software MATLAB

\section{TEORI DASAR}

\section{A. Coupled Tanks [1],[2]}

Coupled Tank tersusun dari dua buah tangki yang dihubungkan oleh sebuah pipa atau lubang saluran. Level cairan pada tangki pertama ditunjukkan sebagai $\mathrm{H}_{1}$ dan $\mathrm{H}_{2}$ adalah level tangki kedua. Bila input kontrol adalah flow $\mathrm{Q}_{1}$, maka variabel yang akan dikontrol adalah kedua Level $\mathrm{H}_{1}$ dan $\mathrm{H}_{2}$, dengan disturbance yang disebabkan oleh variasi flow pada valve $\mathrm{A}$, valve $\mathrm{B}$. Disini akan timbul suatu sistem dengan dua tangki saling berinteraksi.

Sistem Coupled Tank dapat dikonfigurasi sebagai sestem SISO atau sebagai Sistem MIMO melalui manpulasi input dan sectional daerah valve. 


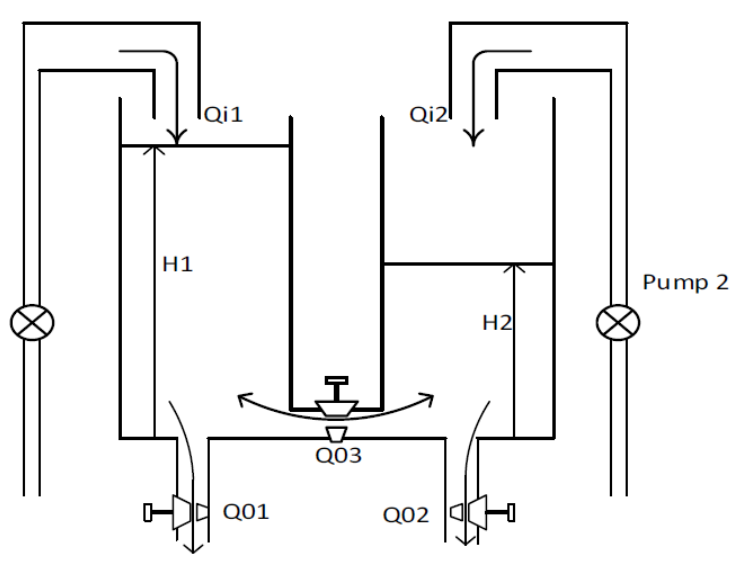

Gambar 1. Sistem Coupled Tank

Level cairan pada tangki pertama ditunjukkan sebagai $\mathrm{H}_{1}$ dan $\mathrm{H}_{2}$ untuk level tangki kedua. Flow cairan yang masuk pada tangki dilambangkan sebagai $\mathrm{Q}_{\mathrm{i}}$. Untuk flow cairan yang keluar dari tangki ditunjukkan sebagai $\mathrm{Q}_{\mathrm{b}}$ untuk tangki pertama, $\mathrm{Q}_{\mathrm{c}}$ tangki kedua, dan $\mathrm{Q}_{\mathrm{a}}$ sebagai flow interaksi antara tangki pertama dan tangki kedua. Sistem Coupled Tanks dapat dikonfigurasikan sebagai sistem Single Input Single Output (SISO), Multi Input Multi Output (MIMO), atau Single Input Multi Output (SIMO) berdasarkan manipulasi masukan pada pompa dan daerah kerja dari rotary valve yang terdapat pada plant Coupled Tanks.

Berdasarkan hukum kesetimbangan massa, persamaan dinamis setiap tangki adalah:

$$
\begin{aligned}
& A_{1} \frac{d H_{2}}{d t}=Q_{i 2}-Q_{o 1}+Q_{o 3} \\
& A_{2} \frac{d H_{2}}{d t}=Q_{i 2}-Q_{o 2}-Q_{o 3}
\end{aligned}
$$

Dimana, $\mathrm{H}_{1}, \mathrm{H}_{2}$ masing-masing adalah tinggi dari cairan pada tangki 1 dan $2, A_{1}$ dan $A_{2}$ adalah luas penampang tangki 1 dan tangki 2. $\mathrm{Q}_{03}$ adalah debit air yang keluar dari tangki1 menuju tangki 2. $\mathrm{Q}_{\mathrm{i} 1}$ dan $\mathrm{Q}_{\mathrm{i} 2}$ adalah debit air dari pompa masing-masing menuju tangki 1 dan tangki 2. $\mathrm{Q}_{\mathrm{o} 1}$ dan $\mathrm{Q}_{\mathrm{o} 2}$ adalah debit air keluar masing-masing dari tangki 1 dan tangki 2.

Dari Persamaan Bernoulli untuk cairan non-kental, mampat cairan dalam aliran didapatkan persamaan sebagai berikut.

$$
\begin{aligned}
& Q_{o 1}=\beta_{1} \cdot a \cdot \sqrt{2 \cdot g} \sqrt{H_{1}}=\beta_{1} . . a \sqrt{2 \cdot g \cdot H_{1}} \\
& Q_{o 1}=\beta_{2} \cdot a \cdot \sqrt{2 \cdot g} \sqrt{H_{2}}=\beta_{2} . . a \sqrt{2 \cdot g \cdot H_{2}} \\
& Q_{o 1}=\beta_{x} \cdot a \cdot \sqrt{2 \cdot g} \sqrt{\left|H_{2}-H_{1}\right|}=\beta_{x} \cdot a \sqrt{2 \cdot g \cdot\left|H_{2}-H_{1}\right|}
\end{aligned}
$$

dimana, $a_{1}, a_{2}$, dan $a_{3}$ merupakan konstanta proporsional dimana bergantung dari koefisien debit area yang saling silang dan konstan gravitasi. Dengan menggunakan nilai dari (2.3) ke (2.5) di (2.1) dan (2.2) persamaan nonlinear menggambarkan dinamika multi-input dan multi-output sistem berasal.

Dinamika plant ini dapat dimodelkan dengan persamaan diferensial sebagai berikut:

$$
\begin{gathered}
A_{1} \frac{d H_{1}}{d t}=q_{1}-\frac{\beta_{1} a \sqrt{g}}{2 \sqrt{H_{1}}} h_{1}+\frac{\beta_{x} a \sqrt{g}}{2 \sqrt{\left|H_{2}-H_{1}\right|}}\left(h_{2}-h_{1}\right) \\
A_{2} \frac{d H_{2}}{d t}=q_{2}-\frac{\beta_{2} \cdot a \sqrt{g}}{2 \sqrt{H_{2}}} h_{2}-\frac{\beta_{x} \cdot a \sqrt{g}}{2 \sqrt{\left|H_{2}-H_{1}\right|}}\left(h_{2}-h_{1}\right)
\end{gathered}
$$

\section{B. Dekopling [3]}

Dekopling digunakan pada plant coupled tank karena plant ini sendiri bersifat MIMO sehingga terjadi interakasi antar input untuk meminimalisir/menghilangkan interaksi maka diperlukan dekopling.

Desain dekopling pada plant dapat dimodelkan sebagai berikut :

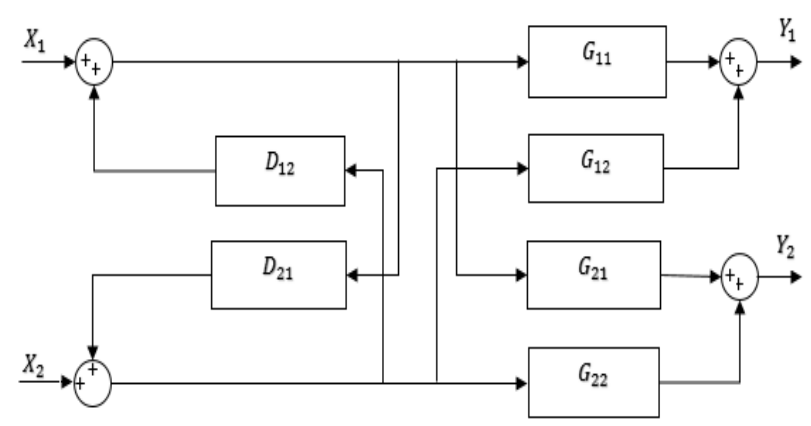

Gambar 2. Plant dengan Decoupling

Dekopler dirancang untuk mengkompensasi interaksi proses yang tidak diinginkan. Untuk memperoleh persamaan pada tiap dekopler maka dilakukan analisa terpisah pada tiap inputoutput

Berikut persamaanya untuk mencari nilai $\mathrm{D}_{12}$ :

$$
\begin{aligned}
& \left(G_{11} D_{12}+G_{12}\right) X_{2}=0 \\
& G_{11} D_{12}+G_{12}=0 \\
& D_{12}=-G_{12} / G_{11}
\end{aligned}
$$

Kemudian untuk mencari nilai $\mathrm{D}_{21}$ berikut persamaannya :

$$
\begin{aligned}
& \left(G_{22} D_{21}+G_{21}\right) X_{1}=0 \\
& G_{22} D_{21}+G_{21}=0 \\
& D_{21}=-G_{21} / G_{22}
\end{aligned}
$$

\section{PERANCANGAN SISTEM}

\section{A. Pemodelan Sistem}

Model matematis dari sistem dengan memanfaatkan hukum fisika maka didapat

$$
\begin{aligned}
& A_{1} \frac{d H_{1}}{d t}=Q_{i 1}-Q_{01}-Q_{0 a} \\
& A_{2} \frac{d H_{2}}{d t}=Q_{i 2}-Q_{02}-Q_{03} \\
& Q_{01}=s_{1} \cdot a_{0} \sqrt{2 g} \cdot \sqrt{H_{1}}=\alpha_{11} \cdot \sqrt{H_{1}} \\
& Q_{02}=s_{2} \cdot a_{0} \sqrt{2 g} \cdot \sqrt{H_{2}}=\alpha_{2} \cdot \sqrt{H_{2}} \\
& Q_{03}=s_{1} \cdot a_{0} \sqrt{2 g} \cdot \sqrt{H_{1}-H_{2}}=\alpha_{\mathrm{a}} \cdot \sqrt{H_{1}-H_{2}} \\
& A_{1} \frac{d H_{1}}{d t}=Q_{i 1}-a_{1} \cdot \sqrt{H_{1}}-\alpha_{1} \cdot \sqrt{H_{1}-H_{2}}
\end{aligned}
$$


$A_{2} \frac{d H_{2}}{d t}=Q_{i 2}-\alpha_{2} \cdot \sqrt{H_{2}}-\alpha_{2} \cdot \sqrt{H_{1}-H_{2}}$

Dimana :

Tabel III.1

Paramater Pemodelan Plant Nonlinier

\begin{tabular}{|c|c|c|c|}
\hline Simbol & Keterangan & Satuan & nilai \\
\hline A & Luas penampang & $\mathrm{cm}^{2}$ & 66,25 \\
\hline A & $\begin{array}{l}\text { Luas penampang } \\
\text { lubang keluaran } \\
\text { tangki } 1 \text { dan } 2 \text { dan } \\
\text { saluran penghubung } \\
\text { antara tangki } 1 \text { dan } \\
2\end{array}$ & $\mathrm{~cm}^{2}$ & 0,1963 \\
\hline & $\begin{array}{l}\text { Rasio bukaan katup } \\
\text { (valve) pada lubang }\end{array}$ & & 0,35903 \\
\hline$\beta_{1}, \beta_{2}$ & $\begin{array}{l}\text { keluaran tangki } 1 \\
\text { dan } 2\end{array}$ & & \\
\hline$\beta_{\mathrm{x}}$ & $\begin{array}{l}\text { Rasio valve antara } \\
\text { tangki } 1 \text { dan } 2\end{array}$ & & 0,38705 \\
\hline $\mathrm{g}$ & Gravitasi & $\mathrm{m}^{2} / \mathrm{s}$ & 9,8 \\
\hline$Q_{i 1}$ & $\begin{array}{l}\text { Debit air yang } \\
\text { masuk pada tangki } 1\end{array}$ & $\mathrm{Cm}^{3} /$ & 2,88 \\
\hline$Q_{i 1}$ & $\begin{array}{l}\text { Debit air yang } \\
\text { masuk pada tangki } 2\end{array}$ & $\mathrm{Cm}^{3} /$ & 2,588 \\
\hline
\end{tabular}

Setelah memasukkan semua parameter dan kemudian disimulasikan pada matlab

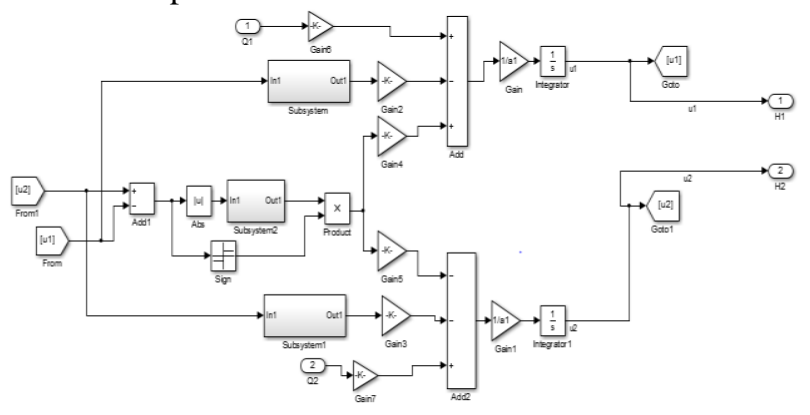

Gambar 3. Simulasi Model Nonlinier

Setelah dilakukan semua parameter dimasukkan ke dalam pemodelan matematika kemudian dilakukan simulasi close dengan model Nonlinier untuk menghasilkan model linier dalam bentuk transformasi laplace.

Simulasi dilakukan dengan cara memberikan respon unit step pada simulasi close model nonlinier sebagai nilai input dari plant kita mendesain model linier dengan memberikan nilai input satu pada setiap nilai input 1 dan input 2 setelah itu kita melihat berapa nilai gain $\mathrm{k}$ yang didapatkan tiap model dan nilai steady state tiap respon untuk mencari nilai $\tau_{\mathrm{s}}$ tiap model linier kemudian yang akan dibentuk dalam transformasi laplace.

Berikut hasil dari pemodelan linier dengan cara pendekatan respon close loop model nonlinier:

$$
\begin{aligned}
G_{11} & =\frac{0,7874}{21 s+1} \\
G_{12} & =\frac{0,0946}{31 s+1}
\end{aligned}
$$

$$
\begin{aligned}
G_{21} & =\frac{0,08915}{29 s+1} \\
G_{22} & =\frac{0,7829}{22 s+1}
\end{aligned}
$$

Bentuk transfer function hasil dari identifikasi sistem sebelumnya yaitu :

$$
\left[\begin{array}{l}
h 1(s) \\
h 2(s)
\end{array}\right]=\left[\begin{array}{ll}
G 11(s) & G 12(s) \\
G 21(s) & G 22(s)
\end{array}\right]\left[\begin{array}{l}
u 1(s) \\
u 2(s)
\end{array}\right]
$$

Dengan u1,u2,h1,h2 merupakan nilai dari debit air yang masuk untuk tangki 1 dan 2 serta tinggi tangki 1 dan tangki 2

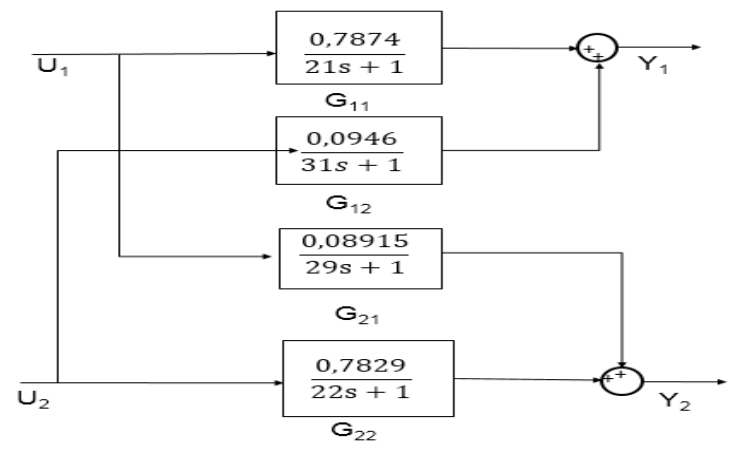

Gambar 4. Transfer Function Plant

\section{B. Dekopling MIMO}

Persamaan dekopling didapat dari memasukkan nilai matriks transfer function Coupled Tank Plant yang telah didapatkan Persamaan matriks didapat dari penghitungan sebagai berikut:

$$
D(s)=\left[\begin{array}{cc}
1 & \frac{-G_{12}(s)}{G_{11}(s)} \\
\frac{-G_{21}(s)}{G_{22}(s)} & 1
\end{array}\right]
$$

Transfer Function yang didapat adalah sebagai berikut:

$$
\begin{gathered}
D_{12}(s)=\frac{1,716 s+0,08387}{25,6 s+0,7998} \\
D_{21}(s)=\frac{1,96 s+0,0891}{22,7 s+0,7829}
\end{gathered}
$$

Gambar dekopling sistem pada penelitian ini ditunjukan pada Gambar 3.3. Dengan adanya metode dekopling pada sistem, maka output $Y 1$ hanya dipengaruhi oleh input $u 1$. Sedangkan output $Y 2$ dipengaruhi oleh input $u 2$

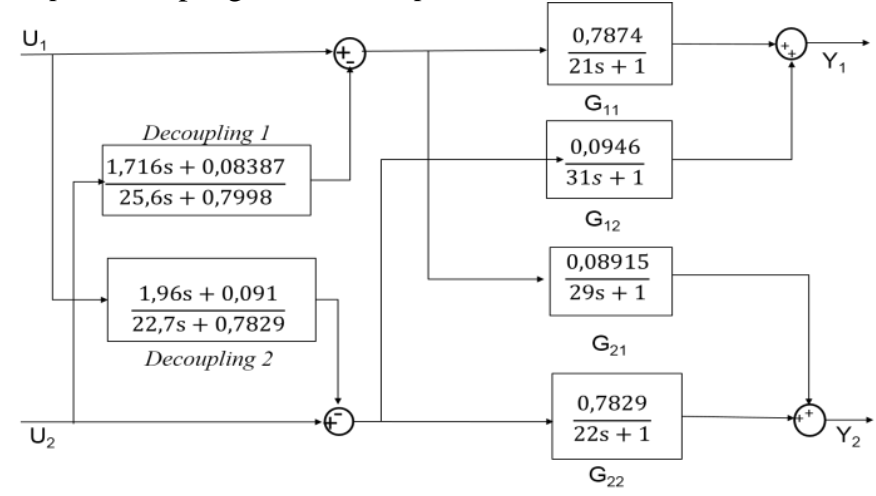

Gambar 5. Hasil Dekopling 


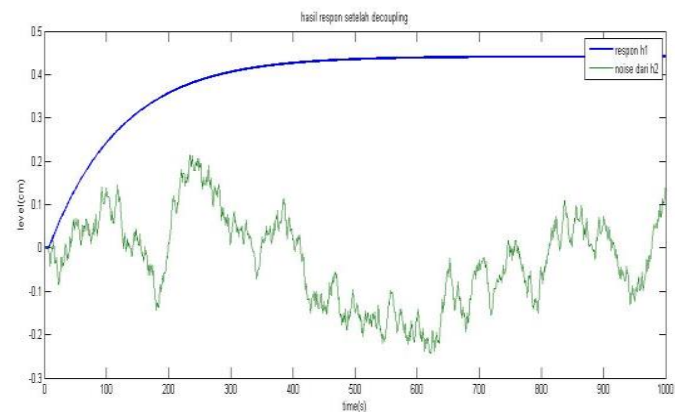

Gambar 6. Pengujian Respon Tangki 1

Setelah diperoleh nilai dekopler $D_{12}$ dan $D_{21}$, maka perlu diuji apakah dekopler sudah dapat menghilangkan interaksi antar input. Pengujian dekopling dilakukan dengan memberi sinyal random dari input $u 2$. Hasil respon pada sistem saat input $u 2$ diberi gangguan ditunjukan pada Gambar 10 dan Gambar 11.

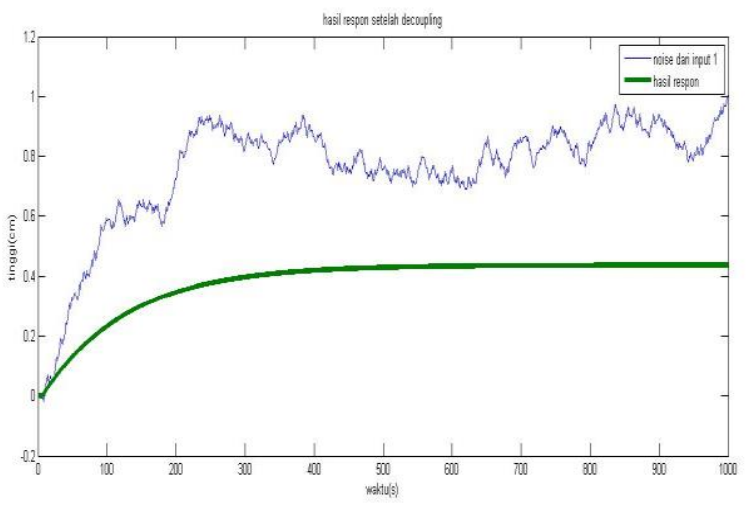

Gambar 7. Pengujian Respon Tangki 2

\section{Perancangan Kontroler}

Kontroler PI-Neural Network terdiri atas kontroler PI sebagai kontroler utama dan Neural Network sebagai algoritma cerdas yang dapat melakukan tuning parameter kontroler PI. Gambardibawah merupakan struktur dari neural network untuk nilai $\mathrm{Kp}$

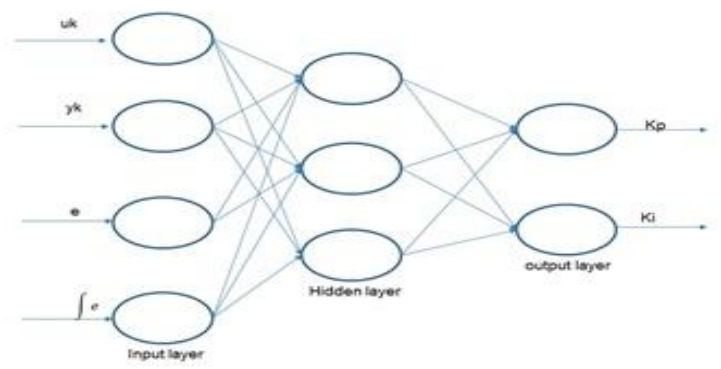

Gambar 8. Struktur Neural Network [5]

Algoritma pembelajaran neural-network yang dipakai adalah feed forward. Input layer neural-network berupa nilai tegangan beban. Persamaan input layer neural-network ditunjukkan pada persamaan

$$
O_{j}^{1}=x(j),(j=1,2, \ldots, M)
$$

M meruapakan jumlah variabel input pada input layer, pada neural network digunakan 4 variabel input. Variabel input dari input layer kemudian menuju output layer.

$$
\begin{aligned}
& n e t^{1}=\sum_{j=0}^{M} w_{j}^{1} o_{j}^{1} \\
& o^{2}=\operatorname{purelin}\left(\text { net }^{1}\right)
\end{aligned}
$$

Untuk merivisi bobot neural-network dipakai algoritma gradient steepest descent sehingga dipenuhi kriteria error kuadarat tiap saat minimum. Formulasi kriteria error kuadrat tiap saat minimum ditunjukkan pada persamaan :

$$
\begin{aligned}
& E(k)=\frac{1}{2}(r(k)-y(k))^{2}=\frac{1}{2} e^{2}(k) \\
& w_{l i}^{(3)}(k+1)=w_{l i}^{(3)}(k)+\Delta w_{l i}^{(3)}(k) \\
& \Delta w_{i j}^{(2)}(k)=\alpha \Delta w_{i j}^{(2)}(k-1) \cdot \delta_{i}^{(2)} O_{j}^{(1)}(k)
\end{aligned}
$$

\section{HASIL DAN ANALISA}

Simulasi dari coupled tank dikatakan baik apabila respon dari tangki 1 dan tangki 2 dapat mengikuti setpoint serta dapat menghilangkan interaksi antara tangki 1 dan tangki 2 setelah dilakukan dekopling

Proses pencarian parameter $\mathrm{Kp}$ dan $\mathrm{Ki}$ menggunakan Algoritma neural network secara online dengan menggunakan model linier maupun model nonlinier plant.

Pada tugas akhir kali ini kita menggunakan 4 kali percobaan yang berbeda beda dengan parameter yang berbeda beda juga.

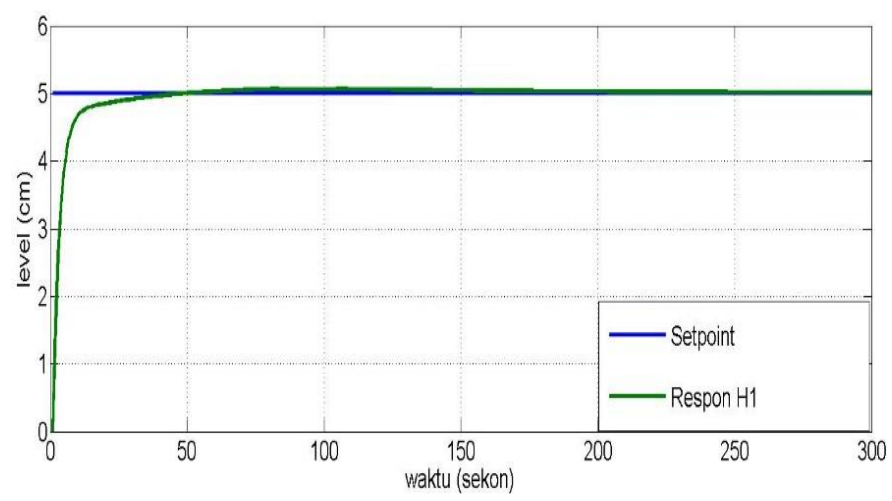

Gambar 9. Hasil Simulasi untuk Tangki 1 Model Linier

Berdasarkan pada Gambar 13 didapatkan bahwa interaksi antara tangki 1 dan tangki 2 sudah dapat dihilangkan dan serta respon pada tangki 1 sudah bisa mencapai setpoint dengan parameter nilai Kp dan Ki sebesar 12,987 dan 0,432 


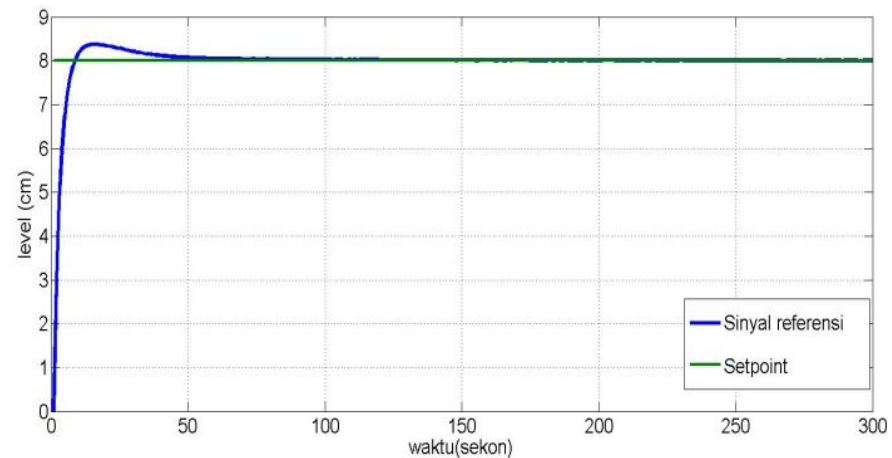

Gambar 10. Hasil simulasi untuk tangki 2 model linier

Berdasarkan pada Gambar 14 didapatkan bahwa interaksi antara tangki 1 dan tangki 2 sudah dapat dihilangkan dan serta respon pada tangki 2 sudah bisa mencapai setpoint dengan parameter nilai Kp dan Ki sebesar 12,987 dan 0,732

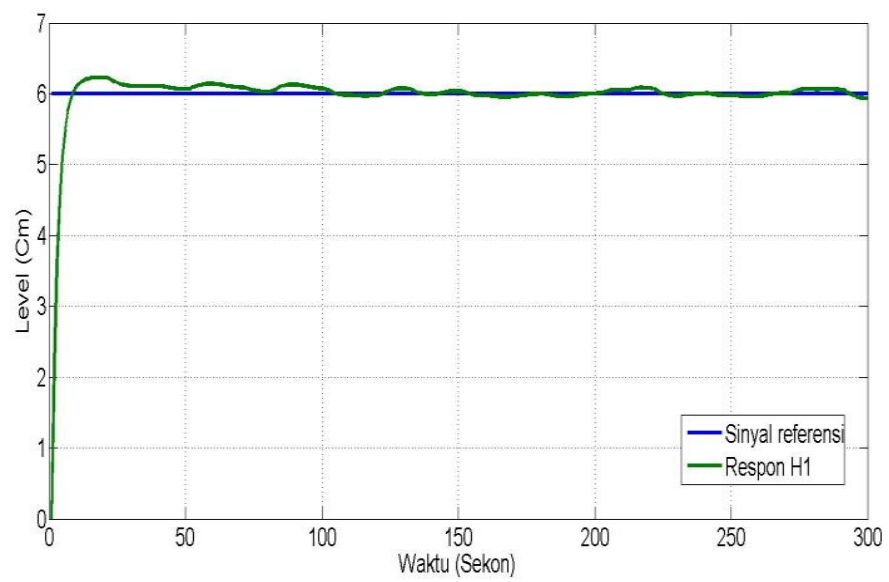

Gambar 11. Hasil simulasi untuk tangki 1 model nonlinier

Berdasarkan pada Gambar 15 didapatkan bahwa interaksi antara tangki 1 dan tangki 2 sudah dapat dihilangkan dan serta respon pada tangki 1 sudah bisa mencapai setpoint dengan parameter nilai Kp dan Ki sebesar 13,987 dan 0,432 terdapat error steady state sebesar $0,025 \%$.

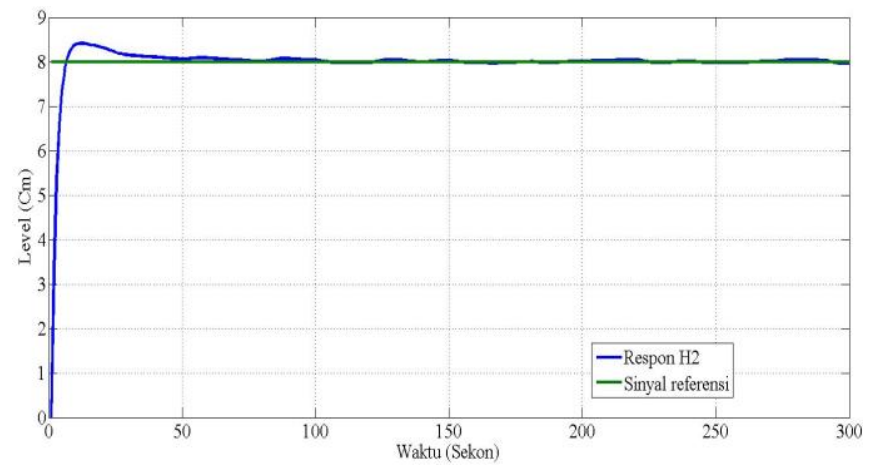

Gambar 12. Hasil Simulasi untuk tangki 2 model nonlinier

Berdasarkan pada Gambar 16 didapatkan bahwa interaksi antara tangki 1 dan tangki 2 sudah dapat dihilangkan dan serta respon pada tangki 1 sudah bisa mencapai setpoint dengan parameter nilai $\mathrm{Kp}$ dan $\mathrm{Ki}$ sebesar 13,0087 dan 1,132. Terdapat error steady state sebesar 0,03\%.

\section{KESIMPULAN}

Dari analisis yang telah dilakukan terhadap 'hasil simulasi maka dapat disimpulkan bahwa:

A. pengaturan level pada coupled tank didapatkan model decoupling secara linear sehingga bisa mengubah perilaku sistem yang sebelumnya bersifat MIMO menjadi SISO dengan gangguan sinyal random pada masukan untuk $\mathrm{H}_{2}$ sebesar $20 \%$ sinyal referensi.

B.Simulasi dengan menggunakan model linier dari plant coupled tank didapatkan nilai untuk Kp optimal yaitu 13,0031 dan Ki optimal yaitu 0,6013 untuk level tangki 1sedangkan untuk level tangki 2 didapatkan nilai optimal untuk Kp yaitu 15,043 dan Ki yaitu 0,8171 .

C.Simulasi plant coupled tank disimulasikan dengan model nonlinier dengan menggunakan decoupling linier efek dari decoupling dapat mengurangi gangguan dari perubahan setpoint salah satu input, meskipun masih terdapat error steady state dengan rata - rata sebesar $0,03 \%$. Pada simulasi model nonlinier menghasilkan nilai $\mathrm{Kp}$ optimal sebesar 12,983 dan Ki sebesar 0,527 untuk level tangki 1, kemudian untuk tangki 2 mendapat nilai Kp optimal sebesar 13,071, Ki optimal sebesar 1,18.

\section{DAFTAR PUSTAKA}

[1] M.S. Ramli, M.A. Ahmad, R.M.T. Raja Ismail, "Comparison of Swarm Adaptive Neural Network Control of a Coupled Tank Liquid Level System", International Conference on Computer Technology and Development, Kinabalu, 13-15 November 2009.

[2] Arjin Numsomran. Tianchai Sukri. Maitree Thumma, "Design 2 Degree Of Freedom (DOF) PI Controller With Decoupling For Coupled Tank Liquid Level System", International Conference on Control and Automation System, Seoul, 13-15 October 2007.

[3] Aryani Fabiany, "Perancangan Kontroler PID-GA untuk Sistem Pengaturan Level dan Pressure pada Simulator Plant Boiler-Turbine dengan Metode Dekopling Sistem MIMO," Tugas Akhir, Jurusan Teknik Elektro, Institut Teknologi Sepuluh Nopember, 2016.

[4] Ogata, Katsuhiko, "Modern Control Engineering", Prentice Hall, New Jersey, 1970

[5] Wicaksono, Agung Setyadi, "Perancangan dan Implementasi Sistem Pengaturan Kecepatan Motor Arus Searah Tanpa Sikat Menggunakan Kontroler PI Berbasiskan Neural-Fuzzy Hibrida Adaptif', Tugas Akhir, Jurusan Teknik Elektro ITS Surabaya, 2016.

[6] Haykin, Simon. "Neural Networks and Learning Machines: Third Edition".United States of America,Pearson Prentice Hall,1999

[7] Dharmawan, Rheza Qashmal, "Desain Autotuning Kontroler PID Berbasis Algoritma Neural Network untuk Sistem Pengaturan Cascade level dan Flow Liquid pada Plant Coupled tanks", Tugas Akhir, Jurusan Teknik Elektro ITS Surabaya, 2016 